\title{
Utilização de resíduos de materiais cerâmicos na adsorção de corante azul de metileno
}

\section{(Use of ceramic wastes in adsorption of methylene blue dyee)}

\author{
L. Dominguini', D. A. Menegaro', T. F. Miguel', M. Dal Bó ${ }^{2}$ \\ ${ }^{1}$ Instituto Federal de Educação, Ciência e Tecnologia de Santa Catarina - IFSC, Rod. SC-443, km 1, Vila Rica, \\ Criciúma, SC 88813-600 \\ ${ }^{2}$ Instituto Federal de Educação, Ciência e Tecnologia do Rio Grande do Sul - IFRS, R. Princesa Isabel 60, \\ Bairro Vila Rica, Feliz, RS 95770-000
}

\begin{abstract}
Resumo
Este trabalho estuda a viabilidade de utilização de resíduos de materiais cerâmicos como agentes de adsorção de corantes utilizados em indústrias têxteis. Resíduos de materiais cerâmicos, oriundos de quebras de tijolos, azulejos e pisos foram selecionados, triturados e moídos a uma granulometria adequada, o que possibilitou o estudo da influência do tipo de material cerâmico (resíduo) e da sua granulometria sobre a adsorção do corante azul de metileno. Os resíduos cerâmicos foram separados em três diferentes granulometrias, fina $\left(0,15 \mathrm{~mm}<\mathrm{D}_{\text {fino }}<0,30 \mathrm{~mm}\right)$, média $\left(0,30 \mathrm{~mm}<\mathrm{D}_{\text {médio }}<1,18 \mathrm{~mm}\right)$ e grossa $\left(1,18 \mathrm{~mm}<\mathrm{D}_{\text {grosso }}<2,00 \mathrm{~mm}\right)$. Testes de absorção de água e absorbância foram efetuados para todos os tipos de cerâmica e granulometrias estudados. Os resultados mostraram que com o resíduo de tijolo, em uma granulometria fina, foi possível adsorver aproximadamente $76 \%$ do corante azul de metileno presente na amostra ensaiada. No entanto, os resultados também mostram que a absorção de água do material cerâmico pode não ser somente o fator que influencia na adsorção do corante.

Palavras-chave: adsorção, materiais cerâmicos, resíduos, azul de metileno.
\end{abstract}

\begin{abstract}
The ceramic residues were separated into three different diameters, thin $\left(0.15 \mathrm{~mm}<D_{\text {thin }}<0.30 \mathrm{~mm}\right)$, medium $\left(0.30 \mathrm{~mm}<D_{\text {medium }}<\right.$ $1.18 \mathrm{~mm})$ and coarse $\left(1.18 \mathrm{~mm}<D_{\text {coarse }}<2.00 \mathrm{~mm}\right)$. Water absorption and absorbance were measured to each type of material and each particle size studied. The results showed that the thin brick waste could adsorb about $76 \%$ of methylene blue dye in the sample tested. However, the results also showed that the water absorption of the ceramic material might not be the only factor that influences the adsorption of the dye.
\end{abstract}

Keywords: adsorption, ceramic materials, wastes, methylene blue.

\section{INTRODUÇÃO}

Nos últimos anos é crescente a preocupação com problemas ambientais, principalmente com a contaminação dos recursos hídricos [1]. Isso elevou o número de trabalhos e pesquisas com o objetivo de otimizar o tratamento dos efluentes químicos industriais. Atualmente, o tratamento de efluentes líquidos utiliza, por exemplo, a adsorção com carvão ativo [2] ou processos oxidativos avançados (POA's) [3], tratamentos que implicam em questões ambientais e custos elevados, respectivamente [4]. Novas alternativas para o tratamento de efluentes líquidos utilizando resíduos surgem como alternativas ambientais. Entre novos materiais encontram-se os resíduos sólidos de curtumes [5], lodo residual têxtil [6] e argilominerais. Dentro da classe dos minerais, cita-se o uso de lama vermelha na remoção de corante reativo azul 19 [7], vermelho do Congo [8] e azul de metileno [9], adsorção de azul de metileno por partículas de argila montmoriloníticas [10] e remoção de corante reativo laranja 16 por zeólitas [11]. Algumas características dos adsorventes das classes dos minerais podem ter influência na remoção de corantes, como argilas esmectitas com diferentes porosidades, área superficial e massa específica [12]. Além disso, subprodutos de origem mineral podem ser utilizados para produção de materiais adsorventes. A carbonização de lamas residuais oriundas de estações de tratamento de água, por exemplo, pode produzir carvões com área superficial entre 100 e $400 \mathrm{~m}^{2} / \mathrm{g}$ [13-15].

Apesar de existirem vários estudos de adsorção de íons metálicos em argilas, são raros os estudos sobre adsorção em cerâmicas. Pode-se citar o trabalho onde se adsorve arsênio em cerâmica produzida com argila "akadama" $[16,17]$.

Resíduos de materiais cerâmicos são gerados durante o processo produtivo industrial de revestimentos cerâmicos (azulejos e pisos, por exemplo) ou de alvenaria estrutural (bloco de cerâmica vermelha). Estes resíduos são oriundos das quebras de produção, podendo em parte ser reaproveitados no mesmo processo. Porém existe grande descarte desses materiais como resíduos sólidos, sendo utilizados também como aterros. Este tipo de resíduo é relativamente pouco 
referido na bibliografia como potencial adsorvente de corantes. Com isso, este trabalho visa estudar a possibilidade da utilização destes resíduos cerâmicos (quebras) em um processo de tratamento de efluentes, atuando como agente de adsorção de corantes utilizados em indústrias têxteis.

$\mathrm{Na}$ região de Criciúma, $\mathrm{SC}$, concentra-se um grande número de indústrias cerâmicas que utilizam argilominerais como matéria-prima, gerando expressiva quantidade de resíduos sólidos que podem apresentar propriedades de absorção $[18,19]$.

Apesar da ampla bibliografia sobre novas alternativas de materiais com alta eficiência de adsorção, não foram encontrados trabalhos sobre a influência do tipo de resíduo cerâmico e sua granulometria na adsorção de corantes utilizados em indústrias têxteis. Neste contexto, este trabalho estuda a viabilidade da utilização de resíduos de materiais cerâmicos na adsorção de corantes utilizados em indústrias têxteis. O objetivo do presente trabalho é avaliar a influência da granulometria e do tipo de cerâmica na adsorção do corante azul de metileno, para posterior aplicação em filtros para o tratamento de efluentes de indústrias têxteis.

\section{EXPERIMENTAL}

\section{Preparação do adsorvente e caracterização do material cerâmico}

Foram selecionados resíduos oriundos das quebras de cerâmica vermelha, monoporosa e piso. As quebras destes materiais são provenientes tanto do processo produtivo quanto do descarte de resíduos sólidos da construção civil. Foram selecionadas somente as quebras provenientes do processo produtivo. A cerâmica vermelha selecionada era proveniente de um processo produtivo que utilizava uma temperatura máxima de $880{ }^{\circ} \mathrm{C}$ durante o processo de queima; já na produção da monoporosa, era $1155^{\circ} \mathrm{C}$, e no processo produtivo do piso cerâmico era $1172{ }^{\circ} \mathrm{C}$. Após a coleta, as amostras foram trituradas em três granulometrias, respeitando as seguintes frações granulométricas: fina $(0,15$ $\left.\mathrm{mm}<\mathrm{D}_{\text {fino }}<0,30 \mathrm{~mm}\right)$, média $\left(0,30 \mathrm{~mm}<\mathrm{D}_{\text {médio }}<1,18 \mathrm{~mm}\right)$ e grossa $\left(1,18 \mathrm{~mm}<\mathrm{D}_{\text {grosso }}<2,00 \mathrm{~mm}\right)$. Para isso, foram utilizadas peneiras com abertura $9,14,48$, e 100 mesh. As demais granulometrias foram descartadas. Os materiais foram lavados e filtrados para eliminar quaisquer grãos fora da faixa granulométrica definida. Na seqüência, os materiais foram secos em estufa a $110^{\circ} \mathrm{C}$ por $24 \mathrm{~h}$. Para determinação da absorção dos materiais, pesou-se $100 \mathrm{~g}$ de cada material e de cada granulometria, e posteriormente imergiu-se em água destilada até cobertura total do material, permanecendo em repouso por $48 \mathrm{~h}$, para saturação total. Na seqüência removeu-se a água excedente por meio de filtração a vácuo. A absorção foi determinada pela diferença percentual entre a massa úmida e a massa seca.

\section{Planejamento fatorial}

Utilizou-se um planejamento fatorial $3^{2}$ para se estudar a influência do tipo de material cerâmico e sua granulometria na adsorção de corantes. Portanto, consideraram-se como fatores o tipo de material cerâmico (cerâmica vermelha, monoporosa e piso) e a granulometria (fina, média e grossa). Uma réplica genuína foi incorporada aos ensaios para garantir resultados com maior expressão estatística. $\mathrm{O}$ planejamento fatorial e a análise estatística foi realizada com o auxílio do programa Statistica $\odot 7.0$.

\section{Ensaio de adsorção}

Para o ensaio de adsorção utilizou-se um erlenmeyer de $250 \mathrm{~mL}$ no qual se adicionou $1 \mathrm{~g}$ do material adsorvente em $150 \mathrm{~mL}$ de uma solução de azul de metileno, com concentração $50 \mathrm{mg} / \mathrm{L}$; a amostra foi mantida sob agitação constante durante $10 \mathrm{~min}$ e a temperatura ambiente foi controlada em $25 \pm 1{ }^{\circ} \mathrm{C}$. Após, a solução foi filtrada por gravidade e coletaram-se alíquotas de $\sim 1 \mathrm{~mL}$. As absorbâncias da solução resultante foram medidas em um espectrofotômetro Spectro SP-22, usando um comprimento de onda de $665 \mathrm{~nm}$.

\section{RESULTADOS E DISCUSSÃO}

As Tabelas I e II mostram os resultados do teste estatístico da ANOVA relativo à absorção de água dos materiais cerâmicos e da absorbância, de acordo com o tipo de cerâmica e granulometria, respectivamente. Segundo o teste estatístico da ANOVA, o valor $p$ indica a significância do fator estudado; com isso pode-se dizer que quando $p<0,05(5 \%)$ o fator apresenta influência sobre a variável resposta com um nível de confiança de $95 \%$. Os resultados evidenciam que tanto o tipo de cerâmica quanto a granulometria afetaram o comportamento da absorção de água e de adsorção da solução de azul de metileno, monitorada por meio da absorbância da solução.

A Fig. 1 mostra o comportamento da absorbância do corante azul de metileno de acordo com o tipo de cerâmica utilizada e da sua granulometria. Os resultados mostram que o tijolo com granulometria fina e média apresentaram maior adsorção do corante, resultando dessa forma em uma absorbância menor. Os resíduos de monoporosa e piso apresentaram pouca adsorção do corante em todas as faixas granulométricas estudadas.

A Fig. 2 mostra o comportamento da absorção de água de acordo com o tipo do resíduo cerâmico utilizado e sua granulometria. Os resultados evidenciam que o resíduo de piso apresentou uma absorção de água menor que os outros tipos de resíduos cerâmicos, decorrente de seu maior grau de sinterização comparado com os outros resíduos cerâmicos.

Comparando os resultados da Fig. 1 e da Fig. 2, notase que não houve uma diferença significativa entre a absorção de água do tijolo e da monoporosa em todas as granulometrias. Por outro lado, os resultados mostraram uma diferença significativa entre a absorbância do resíduo de monoporosa para o resíduo de tijolo. Com isso, os resultados mostram que a absorção de água pode ser apenas uma das 
Tabela I - Resultados do teste estatístico da ANOVA relativo à absorção de água.

[Table I - ANOVA results related to water absorption.]

\begin{tabular}{lccccc}
\hline Fator & $\begin{array}{c}\text { Grau de } \\
\text { liberdade (df) }\end{array}$ & $\begin{array}{c}\text { Soma dos } \\
\text { quadrados } \\
\text { (SS) }\end{array}$ & $\begin{array}{c}\text { Quadrado médio } \\
(\mathrm{MS})\end{array}$ & $\begin{array}{c}\text { Razão } \\
\mathrm{F}\end{array}$ & $\begin{array}{c}\text { Valor } \\
\mathrm{p}\end{array}$ \\
\hline Intersecção & 1 & 11245,00 & 11245,00 & 1280,509 & 0,000000 \\
Tipo de cerâmica (TC) & 2 & 772,85 & 386,43 & 44,004 & 0,000023 \\
Granulometria (G) & 2 & 294,19 & 147,10 & 16,750 & 0,000925 \\
TP*G & 4 & 35,77 & 8,94 & 1,018 & 0,447676 \\
Erro & 9 & 79,03 & 8,78 & & \\
Total & 17 & 1181,85 & & & \\
\hline
\end{tabular}

Tabela II: Resultados do teste estatístico da ANOVA relativo à absorbância.

[Table II: ANOVA results related to absorbance.]

\begin{tabular}{lccccc}
\hline Fator & $\begin{array}{c}\text { Grau de } \\
\text { liberdade } \\
(\mathrm{df})\end{array}$ & $\begin{array}{c}\text { Soma dos } \\
\text { quadrados } \\
(\mathrm{SS})\end{array}$ & $\begin{array}{c}\text { Quadrado médio } \\
(\mathrm{MS})\end{array}$ & $\begin{array}{c}\text { Razão } \\
\mathrm{F}\end{array}$ & $\begin{array}{c}\text { Valor } \\
\mathrm{p}\end{array}$ \\
\hline Intersecção & 1 & 52067611 & 52067611 & 11991,31 & 0,000000 \\
Tipo de cerâmica (TC) & 2 & 2559232 & 1279616 & 294,70 & 0,000000 \\
Granulometria (G) & 2 & 823969 & 411985 & 94,88 & 0,000001 \\
TP*G & 4 & 1393656 & 348414 & 80,24 & 0,000000 \\
Erro & 9 & 39079 & 4342 & & \\
Total & 17 & 4815937 & & & \\
\hline
\end{tabular}

variáveis (fatores) que afetam a adsorção do corante pelo material cerâmico.

A Fig. 3 mostra a curva de nível da absorbância com relação ao tipo de resíduo cerâmico utilizado e sua granulometria.

Evidencia-se claramente que o tijolo com granulometria fina apresentou um valor de absorbância muito menor que os outros materiais. Com isso, o resíduo de tijolo cerâmico mostra-se como um material alternativo o qual pode ser

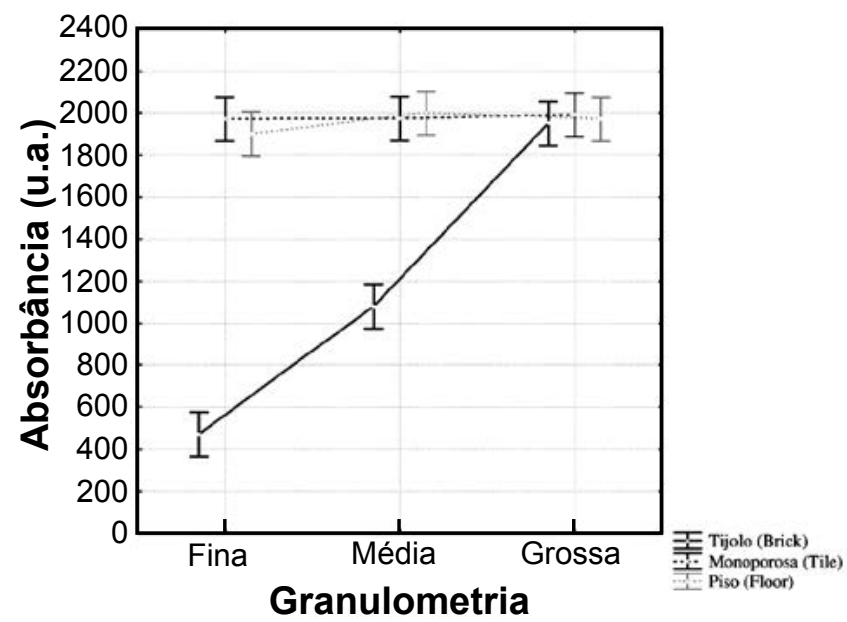

Figura 1: Absorbância do corante azul de metileno de acordo com o tipo de material cerâmico utilizado e sua granulometria.

[Figure 1: Absorbance of blue dye according to ceramic waste type used and the particle size.] utilizado em tratamentos de águas residuais contendo corantes. Alguns estudos mostraram que materiais cerâmicos produzidos a partir de lamas de estação de tratamento de água, por pirólise e ativação química, apresentam menor eficiência para o azul de metileno do que os próprios precursores [20,21]. Isso porque tanto a adsorção quando a absorção de água estão diretamente ligadas à porosidade da amostra e sua respectiva área superficial.

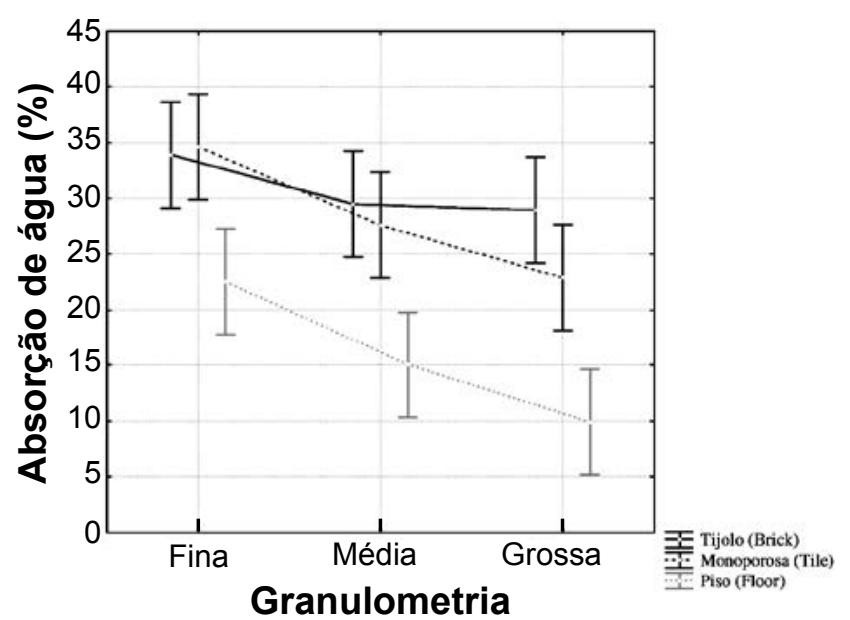

Figura 2: Comportamento da absorção de água de acordo com o tipo de cerâmica e sua granulometria.

[Figure 2: Water absorption behavior according of the ceramic material type and the particle size.] 
$\mathrm{Na}$ calcinação de argilas ocorrem mudanças mineralógicas e químicas em determinadas faixas de temperaturas. Entre $200{ }^{\circ} \mathrm{C}$ e $400{ }^{\circ} \mathrm{C}$ ocorre a combustão da matéria orgânica e piritas; acima desta faixa existe a transformação alotrópica da sílica cristalina em $573{ }^{\circ} \mathrm{C}$. Entre $800{ }^{\circ} \mathrm{C}$ e $930{ }^{\circ} \mathrm{C}$ ocorrem mudanças das estruturas cristalinas [22]. Para materiais cerâmicos fabricados a partir de argilominerais, foi estabelecido o inicio dos processos de vitrificação a $900{ }^{\circ} \mathrm{C}$ [23]. Esse processo modifica os sítios ativos capazes de promover troca iônica nos argilominerais, alterando suas propriedades adsortivas.

Os resultados da adsorção do corante mostraram que o material cerâmico mais vitrificado, o piso, apresentou menor absorção de água e também menor adsorção do corante azul de metileno. Por outro lado, o material com menor vitrificação, o tijolo, apresentou maior absorção de água e também maior adsorção de corante. Resumidamente, o trabalho mostrou que materiais cerâmicos com menor grau de vitrificação e maior absorção de água incrementaram a adsorção do corante azul de metileno.

A Fig. 4 representa a estrutura química do azul de metileno e ilustra os polos existentes na estrutura do corante que permite a interação entre este e os poros existentes nos materiais cerâmicos, permitindo dessa forma a adsorção.

Uma possível explicação para a relação entre o grau de vitrificação e a capacidade adsortiva está relacionada como

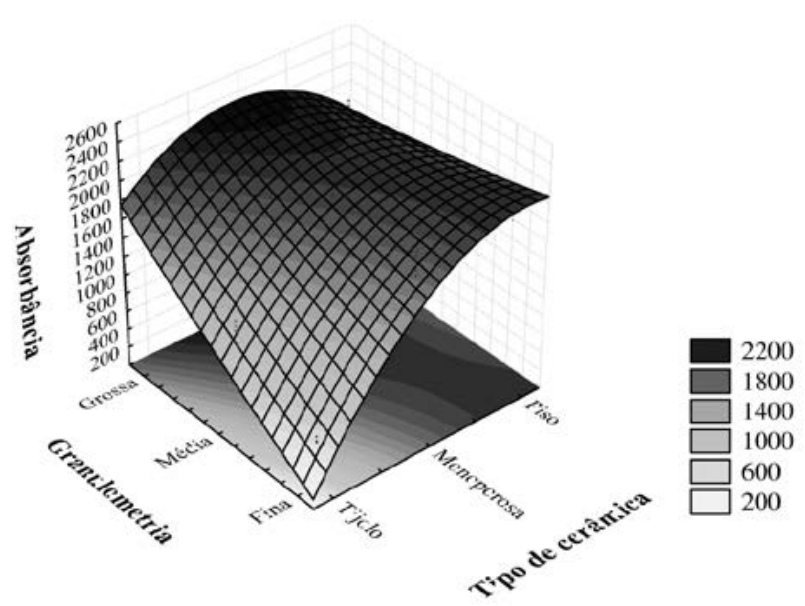

Figura 3: Curva de nível da absorbância de acordo com o tipo de cerâmica e sua granulometria.

[Figure 3: Response surface of absorbance according ceramic waste type and the particle size.]

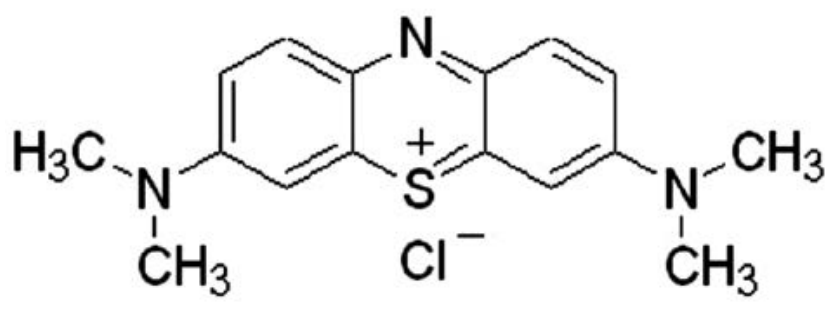

Figura 4: Estrutura química do corante azul de metileno [24]. [Figure 4: Chemical structure of methylene blue dye [24].] aumento na temperatura de sinterização, que acarreta em um incremento no grau de vitrificação, reduzindo assim o número de sítios ativos no material cerâmico e, por conseqüência, sua capacidade adsortiva.

\section{CONCLUSÕES}

Estudou-se a possibilidade de utilização de resíduos de materiais cerâmicos como agentes de adsorção de corantes utilizados em processos têxteis. Os resultados mostraram que o resíduo de tijolo é um material com alta capacidade de adsorção de corantes. Os melhores resultados foram obtidos com resíduo de tijolo em uma granulometria fina, compreendida entre $0,30 \mathrm{~mm}$ e $0,15 \mathrm{~mm}$. Com este resíduo, foi adsorvido $\sim 76 \%$ do corante azul de metileno na amostra. Notou-se também que a absorção de água pode não ser a única variável (fator) responsável pela adsorção dos corantes, já que a monoporosa e o tijolo apresentaram a mesma absorção de água e diferentes valores de adsorção durante os ensaios. Trabalhos futuros com ensaios de área superficial e/ou do grau de vitrificação podem auxiliar na otimização do processo de adsorção de corantes utilizando resíduos industriais. Este trabalho mostra a viabilidade de utilização de resíduos de materiais cerâmicos no tratamento de efluentes de indústrias têxteis, contribuindo dessa forma com o meio ambiente.

\section{AGRADECIMENTOS}

Ao CNPq, ao IFRS (Campus Feliz) e ao IFSC (Campus Criciúma) pelo financiamento.

\section{REFERÊNCIAS}

[1] E. G. R. Davies, S. P. Simonovic, Adv. Water Resources 34, 6 (2011) 684.

[2] V. V. S. Guilarduci, J. P. Mesquita, P. B. Martelli, H. F. Gorgulho, Química Nova 29 (2006) 1226.

[3] M. E. Nagel-Hassemer, L. A. Coral, F. R. Lapolli, M. T. S. P. Amorim, Química Nova 35 (2012), 900.

[4] G. Zanella, M. Scharf, G. A. Vieira, P. Peralta-Zamora, Química Nova 33 (2010) 1039.

[5] R. M. Dallago, A. Smaniotto, L. C. A. Oliveira, Química Nova 28 (2005) 433.

[6] A. R. Vasques, S. M. A. G. U. Souza, L. Weissenberg, A. A. U. Souza, J. A. B. Valle, Eng. Sanit. Amb. 16 (2011) 245.

[7] K. C. Souza, M. L. P. Antunes, F. T. Conceição, Química Nova 36 (2013) 651.

[8] A. Tor, Y. Cengeloglu. J. Hazardous Mater. 138, 2 (2006) 409.

[9] S. Wang, Y. Boyjoo, A. Choueib, Z. H. Zhu. Water Res. 39, 1 (2005) 129.

[10] R. A. Sartori, L. C. Morais, N. Consolin-F., D. D. Marques, F. Gessner, Química Nova 34 (2011) 584.

[11] T. E. M. Carvalho, D. A. Fungaro, J. C. Izidoro, Química Nova 33 (2010) 358.

[12] C. Vieira, C. L., G. L. Silva, M. G. C. Silva, V. L. Silva 
"Avaliação do processo de adsorção na remoção de cor em efluentes de lavanderias industriais de jeans por argila esmectita brasileira", VI Cong. Bras. Eng. Quim. Inic. Cient., Campinas, SP (2005).

[13] A. Bagreev, S. Bashkova, D. C. Locke, T. J. Bandosz, Environ. Sci. \& Technol. 35, 7 (2001) 1537.

[14] J. H. Tay, X. G. Chen, S. Jeyaseelan, N. Graham, Chemosphere 44, 1 (2001) 45.

[15] M. J. Martin, A. Artola, M. D. Balaguer, M. Rigola, J. Chem. Technol. \& Biotechnol. 77, 7 (2002) 825.

[16] T. L. Zanin, "Estudo de adsorção de cátions em cerâmica com zeólita de cinzas de carvão mineral", Universidade Federal do Paraná, Curitiba, PR (2011).

[17] R. Chen, Z. Zhang, C. Feng, K. Hu, M. Li, Y. Li, K. Shimizu, N. Chen, N. Sugiura, Microporous Mesoporous Mater. 131, 1-3 (2010) 115.
[18] I. M. G. Santos, J. M. Silva, M. F. S. Trindade, L. E. B. Soledade, A. G. Souza, C. A. Paskocimas, E. Longo, Cerâmica 51 (2005) 144.

[19] M. Cargnin, S. M. A. G. U. Souza, A. A. U. Souza, A. D. Noni Jr., Cerâmica 57 (2011) 461.

[20] M. Otero, F. Rozada, L. F. Calvo, A. I. García, A. Morán, Biochem. Eng. J. 15, 1 (2003) 59.

[21] L. F. Calvo, M. Otero, A. Morán, A. I. García, Bioresource Technol. 80, 2 (2001) 143.

[22] P. Souza Santos, H. S. Santos, "Ciencia e Tecnologia de Argilas”, E. Blucher, S.Paulo, SP (1989).

[23] W. D. Callister, "Fundamentos de ciência e engenharia de materiais: uma abordagem integrada", LTC Ed. (2006).

[24] V. S. Ferreira-Leitão, M. E. A. de Carvalho, E. P. S. Bon, Dyes and Pigments 74, 1 (2007), 230-236.

(Rec. 31/08/2013, Rev. 21/10/2013, Ac. 21/11/2013) 